\title{
Análise do nível de implantação do processo de autoavaliação nas faculdades privadas de Salvador, Bahia
}

\author{
Eniel do Espírito Santo \\ Xisto Lucas Travassos \\ Sabrina Oliveira Caribé
}

Resumo: Este artigo tem como objetivo apresentar uma análise realizada sobre o nível de implantação do processo de autoavaliação nas faculdades privadas de Salvador na visão dos coordenadores da CPA. Para tanto, realizou-se uma pesquisa com 14 faculdades privadas de Salvador, utilizando como instrumento de coleta de dados, o questionário, com questões mistas (fechadas e abertas). As conclusões indicam que menos da metade das faculdades analisadas possui o processo de autoavaliação implantado de forma suficiente, ou seja, atendendo aos requisitos mínimos exigidos pelo INEP.

Palavras-chave: Avaliação da educação superior. SINAES. Avaliação institucional e autoavaliação.

An Analysis of the level of implementation of the self-evaluation process in private colleges of Salvador, Bahia

\begin{abstract}
This article aims to present an analysis on the level of implementation the self-evaluation process in private colleges of Salvador from the perspective of the coordinators of CPAs (internal institutional evaluation commissions). Therefore, we carried out a survey in 14 private colleges in Salvador, using as an instrument of data collection, a questionnaire with mixed (open and closed) questions. The findings indicate that less than half of the colleges analyzed had a sufficiently implemented self-evaluation process. These colleges do not meet the minimum requirements established by INEP.
\end{abstract}

Key words: Higher education-evaluation. SINAES. Institutional evaluation and self-evaluation.

\section{Introdução}

O Sistema Nacional de Avaliação da Educação Superior - SINAES, criado em 2004, incorporou grande parte dos princípios e diretrizes do PAIUB, sistema sustentado no princípio da adesão voluntária das universidades e que concebia a autoavaliação como etapa inicial do processo que se estendia a toda a instituição e se completava com a avaliação externa. O SINAES nasceu combinando as vertentes de regulação e avaliação educativa, em suas dimensões interna e externa. $\mathrm{O}$ caráter regulatório pode ser evidenciado por meio dos atos de credenciamento e recredenciamento das instituições e autorização, reconhecimento e renovação do reconhecimento dos cursos, conforme previsto em legislação específica. 
Esse sistema que permite maior abrangência e integração dos processos avaliativos seja com foco na instituição, nos cursos ou nos estudantes, desde que devidamente implementado, apresenta condições para melhorar a qualidade do ensino superior e a gestão das instituições de ensino. Considerando que a autoavaliação é a base de todo esse sistema, que busca analisar de forma detalhada as instituições de ensino, em dimensões como: missão, políticas de ensino, pesquisa e extensão, infraestrutura, responsabilidade social, sustentabilidade financeira, entre outras é fundamental entender como está a implementação desse processo nas faculdades privadas de Salvador objetivando identificar o compromisso dessas faculdades em oferecer um ensino de qualidade para a população.

Diante do exposto, objetivou-se nesse estudo analisar o processo de autoavaliação, parte integrante de um dos três elementos do SINAES, a Avaliação das Instituições de Educação Superior (AVALIES), com o propósito de identificar o nível de implantação do processo de autoavaliação nas faculdades privadas de Salvador na visão dos coordenadores da Comissão Própria de Avaliação - CPA. A autoavaliação deve ser utilizada pelas instituições de ensino como uma ferramenta de gestão que possa auxiliar as comunidades acadêmicas na tomada de decisões quanto à realidade dos seus cursos e das suas instituições.

Para tanto, realizou-se uma pesquisa com 14 faculdades privadas de Salvador, utilizando como instrumento de coleta de dados, o questionário, com questões mistas (fechadas e abertas). Em seguida, foram definidos critérios que mesclavam as etapas de um processo de autoavaliação com os requisitos estabelecidos pela Comissão Nacional de Avaliação da Educação Superior - CONAES para estabelecer o nível de implantação desse processo de autoavaliação.

\section{Avaliação Institucional}

O SINAES foi instituído em 14 de abril de 2004, por meio da publicação da Lei 10.861, publicada no Diário Oficial da União $n^{\circ} 72$, no dia 15 de abril de 2004. A referida Lei, em seu artigo $1^{\circ}$, estabelece que:

Art. $1^{\circ}$ Fica instituído o Sistema Nacional de Avaliação da Educação Superior SINAES, com o objetivo de assegurar processo nacional de avaliação das instituições de educação superior, dos cursos de graduação e do desempenho acadêmico de seus estudantes, nos termos do art. $9^{\circ}$, VI, VIII e IX, da Lei n ${ }^{\circ}$ 9.394, de 20 de dezembro de 1996 (BRASIL, 2004b). 
A partir de então, o sistema avaliativo do SINAES passou a se constituir num referencial básico para o processo de regulação do ensino superior, que é coordenado e supervisionado pela CONAES e operacionalizado pelo Instituto Nacional de Ensino e Pesquisa Anísio Teixeira (INEP).

Os processos de avaliação devem ser contínuos e permanentes, não pontuais e fragmentados, com o objetivo de criar uma cultura da avaliação educativa internalizada no cotidiano. Quando o processo é fragmentado, a avaliação acaba se tornando apenas procedimentos burocráticos e legalistas, perdendo seu potencial de transformação a partir de reflexões compartilhadas e permanentemente exercitadas (SINAES, 2009).

Portanto, o SINAES é um sistema global e integrado composto por três elementos principais: I) Avaliação das Instituições de Educação Superior (AVALIES), composta pelas avaliações internas e externas das instituições; II) Avaliação dos cursos de graduação (ACG), realizada por comissões designadas para este fim; III) Avaliação de Desempenho dos Estudantes, realizada mediante a participação dos ingressantes e concluintes de cursos previamente selecionados a cada ano para a realização do Exame Nacional de Desempenho dos Estudantes (ENADE).

\section{Avaliação de Cursos de Graduação (ACG)}

A Lei $10.861 \mathrm{em}$ seu art. $4^{\circ}$ estabelece que:

Art. $4^{\circ}$ A avaliação dos cursos de graduação tem por objetivo identificar as condições de ensino oferecidas aos estudantes, em especial as relativas ao perfil do corpo docente, às instalações físicas e à organização didático-pedagógica.

$\S 1^{\circ}$ A avaliação dos cursos de graduação utilizará procedimentos e instrumentos diversificados, dentre os quais obrigatoriamente as visitas por comissões de especialistas das respectivas áreas do conhecimento.

$\S 2^{\circ}$ A avaliação dos cursos de graduação resultará na atribuição de conceitos, ordenados em uma escala com 5 (cinco) níveis, a cada uma das dimensões e ao conjunto das dimensões avaliadas. (BRASIL, 2004b).

Esse elemento do SINAES, objetiva identificar o perfil do corpo docente, bem como a organização didático-pedagógica e as instalações físicas oferecidas aos alunos. As avaliações in loco, mencionadas anteriormente são os atos de autorização, reconhecimento e renovação de reconhecimento realizados por especialistas correspondentes às diversas áreas de conhecimento. 


\section{Avaliação de Desempenho dos Estudantes}

A avaliação de desempenho dos estudantes de graduação é realizada mediante a aplicação do ENADE, previsto no art. $5^{\circ}$ da Lei $\mathrm{n}^{\circ} 10.861$, de 2004, para avaliar $\left(\S 1^{\circ}\right)$ o transcrito a seguir:

[...] aferirá o desempenho dos estudantes em relação aos conteúdos programáticos previstos nas diretrizes curriculares do respectivo curso de graduação, suas habilidades para ajustamento às exigências decorrentes da evolução do conhecimento e suas competências para compreender temas exteriores ao âmbito específico de sua profissão, ligados à realidade brasileira e mundial e a outras áreas do conhecimento (BRASIL, 2004b).

O ENADE é considerado componente curricular obrigatório dos cursos, de acordo com a Lei ${ }^{\circ} 10.861 / 2004$, Art. $5^{\circ}, \S 5^{\circ}$, com aplicação periódica, destinado aos discentes do final do primeiro e do último ano do curso, pretendendo perceber o quanto a IES colaborou com a formação daquele aluno. Até o ano de 2008 a aplicação do ENADE era amostral, que variava entre $60 \%$ e $65 \%$ do total de estudantes ingressantes e concluintes dos cursos que eram selecionados para o exame. Em 2009, o ENADE passou a ser universal e não mais amostral.

Caso o discente não compareça para a realização do exame estará em situação irregular perante o MEC devido a obrigatoriedade desse componente curricular e não poderá ser graduado.

\section{Avaliação de Instituições de Educação Superior (AVALIES)}

A avaliação institucional organiza os diversos instrumentos avaliativos de acordo com o princípio da integração, desenvolvendo-se em dois momentos: a avaliação interna ou autoavaliação e a avaliação externa.

A avaliação institucional, tanto na dimensão interna, quanto na externa, incorpora as informações e os resultados de outros instrumentos, tais como o Censo da Educação Superior, o Cadastro das Instituições de Educação Superior, a avaliação feita pelas comissões e a avaliação da Pós Graduação (CAPES), colocando-se numa perspectiva de globalidade (SINAES, 2009).

A avaliação institucional é o processo que envolve o esforço da instituição em se conhecer e ser conhecida por outros setores da sociedade e que, articulada ao planejamento, tem grande potencial para contribuir na gestão estratégica (TRIGUEIRO, 2004). 


\section{Autoavaliação das Instituições}

De acordo com a CONAES, a autoavaliação tem por objetivos produzir conhecimentos sobre a realidade das IES; compreender os significados do conjunto das atividades para melhorar a qualidade educativa e alcançar maior relevância social; identificar as potencialidades e as fragilidades; aumentar a consciência pedagógica e a capacidade profissional do corpo docente e técnico-administrativo; fortalecer as relações de cooperação entre os diversos atores institucionais; tornar mais efetiva a vinculação da instituição com a comunidade; e prestar contas à sociedade (BRASIL, 2011a).

Visando a implementação desse processo nas instituições de educação superior e, em especial a sua operacionalização, a CONAES aprovou dois documentos: Orientações gerais para o roteiro da autoavaliação ${ }^{1}$ e Sugestão de Roteiro do Relatório de Autoavaliação.

Nesse primeiro documento, a CONAES define alguns requisitos para que possamos considerar adequada a implementação de um processo de autoavaliação em uma instituição de ensino superior, a saber: a existência de uma equipe de coordenação para realizar este trabalho, participação da comunidade acadêmica e da comunidade externa, compromisso explícito dos dirigentes das IES, sistematização de informações válidas e confiáveis e por fim o uso efetivo dos resultados do processo avaliativo.

Para Sousa (2006), um bom processo avaliativo é aquele que é compreendido, com facilidade, por todos os atores da comunidade acadêmica. Esse processo não deve ser subordinado aos interesses de uma gestão universitária, mas a própria gestão poderá entendê-lo como uma forma legítima de retratar as dificuldades, as facilidades e a busca de caminhos.

Os trabalhos de autoavaliação devem ser realizados em três etapas: preparação; desenvolvimento e consolidação. A primeira etapa é composta por três fases: constituição da CPA, a Sensibilização e a Elaboração do Projeto de Avaliação.

A constituição de uma CPA, no âmbito de cada instituição e sua forma de composição, está estabelecida na Portaria $\mathrm{n}^{\mathrm{o}} 2.051 / 04$, em seu artigo $7^{\circ}, \S 2^{\mathrm{o}}$ :

A forma de composição, a duração do mandato de seus membros, a dinâmica de funcionamento e a especificação de atribuições da CPA deverão ser objeto de regulamentação própria, a ser aprovada pelo órgão colegiado máximo de cada instituição de educação superior, observando-se as seguintes diretrizes:

1 Esse documento apresenta referências para a apreensão da qualidade das instituições de educação superior, sejam elas faculdades, centros universitários ou universidades, de caráter público ou privado. 
I - necessária participação de todos os seguimentos da comunidade acadêmica (docente, discente e técnico administrativo) e de representantes da sociedade civil organizada, ficando vedada à existência de maioria absoluta por parte de qualquer um dos segmentos representados;

II - ampla divulgação de sua composição e de todas as suas atividades. (BRASIL, 2004d).

Na fase da sensibilização, a CPA deve obter a mais ampla e efetiva participação da comunidade interna nas discussões e estudos, sendo recomendável que nesse processo também conte com a colaboração de membros da comunidade externa, especialmente de ex-alunos e representantes daqueles setores sociais mais diretamente envolvidos com a IES (SINAES, 2009).

Cabe ressaltar que a sensibilização deve estar presente em todos os momentos do processo avaliativo, visto que sempre haverá sujeitos novos no processo: sejam estudantes, membros do corpo docente ou corpo técnico-administrativo (BRASIL, 2004a).

Após a sensibilização e ampla discussão com a comunidade acadêmica sobre o processo de autoavaliação a IES deve elaborar um projeto de avaliação. Neste instrumento, é importante que haja um planejamento para a execução das ações inerentes ao processo avaliativo e seja coerente com as características da instituição. O projeto deve conter o objetivo da instituição com a autoavaliação, as estratégias, metodologia e ações necessárias ao processo e consequentemente às ações com responsáveis e prazos definidos para que o processo seja implementado.

A segunda etapa é a de desenvolvimento, que busca executar as atividades constantes no planejamento, incluindo ações de sensibilização, sistematização das ideias, demandas e sugestões oriundas de reuniões, seminários para divulgação da documentação normativa do SINAES, construção dos instrumentos de coleta de dados, organização dos dados, realização de análises, cruzamentos e interpretação dos dados com vistas a construir os relatórios parciais e discutir esses resultados com a comunidade acadêmica.

De acordo com a Lei 10.861 em 14 de abril de 2004, no seu artigo $3^{\circ}$, a avaliação das instituições de educação deve considerar diferentes dimensões institucionais, sendo as dez dimensões obrigatórias:

I - a missão e o plano de desenvolvimento institucional;

II - a política para o ensino, a pesquisa, a pós-graduação, a extensão e as respectivas formas de operacionalização, incluídos os procedi- 
mentos para estímulo à produção acadêmica, as bolsas de pesquisa, de monitoria e demais modalidades;

III - a responsabilidade social da instituição, considerada especialmente no que se refere à sua contribuição em relação à inclusão social, ao desenvolvimento econômico e social, à defesa do meio ambiente, da memória cultural, da produção artística e do patrimônio cultural;

IV - a comunicação com a sociedade;

$\mathrm{V}$ - as políticas de pessoal, as carreiras do corpo docente e do corpo técnico administrativo, seu aperfeiçoamento, desenvolvimento profissional e suas condições de trabalho;

VI - organização e gestão da instituição, especialmente o funcionamento e representatividade dos colegiados, sua independência e autonomia na relação com a mantenedora, e a participação dos segmentos da comunidade universitária nos processos decisórios;

VII - infra-estrutura física, especialmente a de ensino e de pesquisa, biblioteca, recursos de informação e comunicação;

VIII - planejamento e avaliação, especialmente os processos, resultados e eficácia da Autoavaliação institucional;

IX - políticas de atendimento aos estudantes;

$\mathrm{X}$ - sustentabilidade financeira, tendo em vista o significado social da continuidade dos compromissos na oferta da educação superior. (BRASIL, 2004b).

Para análise dessas dimensões são descritas questões orientadoras, e um grande número de indicadores que tem como função permitir a adequada análise às propostas. Tais indicadores, por sua vez, para serem corretamente analisados, exigem um levantamento e cruzamento de dados da instituição.

A avaliação em suas diversas dimensões é permanente, mas se realiza por ciclos, apresentando periodicamente os seus resultados. $\mathrm{O}$ ciclo avaliativo completo deve obedecer a um período máximo de três anos. Entretanto, anualmente as IES tornarão públicas as informações relativas a alguns aspectos do seu processo contínuo, mais especificamente as informações demandadas pelo Cadastro e Censo da Educação Superior.

Para Sousa (2006), a função básica da autoavaliação é a de produzir dados, informações que permitam a tomada de decisões. Além disso, exige o desenvolvimento de uma cultura avaliativa, de utilização de dados de diagnóstico, que precisa ser construída.

Portanto, a autoavaliação atinge a sua função quando a CPA menciona os avanços da instituição e sinaliza seus desafios com sugestões de modificações 
a partir das análises realizadas. Complementando esse ciclo, as IES precisam utilizar os resultados do processo de autoavaliação para reforçar ações que estão atendendo às expectativas da comunidade e tendo efeito positivo no ensino, pesquisa e na extensão e para realizar as modificações que visam corrigir eventuais equívocos cometidos na gestão acadêmica, estabelecendo assim uma relação de cooperação com a administração superior da IES (BRASIL, 2011, p. 88).

Contudo, no estudo realizado pelo INEP $^{2}$ em 2009, pode-se observar que apesar da maioria das IES (61\%) sugerirem as ações corretivas a partir do processo de autoavaliação, um percentual muito baixo $(25,6 \%)$, realiza as ações sinalizadas pelo processo de autoavaliação.

A terceira etapa é de consolidação, na qual deve haver a construção do relatório final, a sua divulgação e um balanço crítico do processo avaliativo.

Para a construção do relatório deve haver uma intensa discussão dos dados. É importante que ele seja capaz de incorporar, quando estiverem disponíveis, os resultados das avaliações de cursos e de desempenho de estudantes (BRASIL, 2004a).

O público alvo do relatório são os membros da comunidade acadêmica, os avaliadores externos e a sociedade. Portanto, esse deve ser um relatório de caráter analítico e interpretativo dos resultados obtidos, porém, não perdendo a clareza nas informações.

Com o relatório pronto, inicia-se a etapa de divulgação do mesmo. Essa divulgação deve ser ampla atingindo a comunidade acadêmica e a sociedade. Deve existir um acompanhamento sistemático das ações definidas e, quando concluídas, a divulgação para a comunidade acadêmica.

Ao final do processo é necessário realizar uma análise de todo o processo avaliativo, visando uma análise das estratégias utilizadas, das dificuldades encontradas e dos avanços apresentados. A cada novo ciclo avaliativo deve-se levar em conta os acertos e eventuais equívocos do processo anterior (SINAES, 2009).

Essa última etapa pode ser considerada como a mais crítica dentro do processo de autoavaliação, pois contempla a elaboração do relatório final onde devem constar todas as evidências da autoavaliação, incluindo o seu replanejamento.

A postagem deste relatório no sistema e-MEC é o início de uma das etapas de regulação do SINAES, a avaliação externa das instituições.

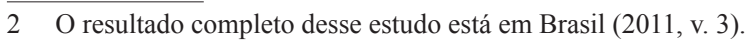




\section{Avaliação Externa das Instituições}

A avaliação externa fundamentada no SINAES e pautada no projeto de autoavaliação da instituição e seus relatórios, bem como em instrumentos comuns a todas as IES, tem por objetivo contribuir para o autoconhecimento e aperfeiçoamento das atividades desenvolvidas pela instituição, levando em consideração o importante princípio do respeito a diversidade e à identidade institucional.

Nesse sentido, a autoavaliação e a avaliação externa devem estar completamente articuladas, pois ambos os processos são concebidos como subsídios fundamentais para a formulação de diretrizes para as políticas púbicas de educação superior e para a gestão das instituições, visando a melhoria da qualidade de suas ações.

A avaliação externa é realizada por comissões designadas pelo INEP, segundo diretrizes estabelecidas pela CONAES. O processo de avaliação externa tem como referência os padrões de qualidade para a educação superior contidos nos instrumentos de avaliação e nos relatórios das autoavaliações realizados pelas CPAs. Esse tipo de avaliação, segundo o SINAES, deve se orientar por uma visão multidimensional, buscando integrar a sua natureza formativa e de regulação numa perspectiva de globalidade.

\section{Comissão Própria de Avaliação}

A CPA é responsável por conduzir o processo de autoavaliação nas IES. O inciso II da Lei 10.861, ressalta a importância da atuação autônoma da CPA em relação a conselhos e demais órgãos colegiados das instituições. Augusto (2007), em pesquisa realizada com as CPAs das IES de Campinas, identificou que todos os coordenadores declararam ter autonomia e liberdade de atuação, porém, por meio das conversas informais percebeu-se que existem CPAs que não têm autonomia para trabalhar. Carneiro (2007), em estudo realizado com as instituições de ensino superior privadas de Salvador, identificou que 52\% dos respondentes concordaram que a CPA funciona de forma autônoma, enquanto $30 \%$ demonstrou indecisão, e 18\% discordou, o autor reforçou que esse resultado pode indicar que a relação de autonomia entre CPA e IES se apresenta de forma parcial na percepção dos coordenadores das CPAs, umas vez que o percentual acumulado de indecisos e discordantes ficou muito próximo do percentual daqueles que concordam. É importante que os coordenadores de CPA e consequentemente as instituições de ensino não permitam que essa "falta de autonomia" deixem influenciar negativamente na fidedignidade dos dados apresentados no 
processo de autoavaliação. Uma vez que, isso tornaria o processo meramente burocrático não contribuindo assim para identificação das melhorias necessárias na instituição e, por conseguinte, no ensino superior brasileiro.

A constituição de uma CPA, no âmbito de cada instituição e sua forma de composição, está estabelecida na Portaria $\mathrm{n}^{\mathrm{o}} 2.051 / 04$, em seu artigo $7^{\circ}, \S 2^{\mathrm{o}}$ :

I - necessária participação de todos os seguimentos da comunidade acadêmica (docente, discente e técnico administrativo) e de representantes da sociedade civil organizada, ficando vedada à existência de maioria absoluta por parte de qualquer um dos segmentos representados;

II - ampla divulgação de sua composição e de todas as suas atividades. (BRASIL, 2004d).

Entretanto, mesmo diante de uma legislação para regulamentar os requisitos mínimos necessários à composição da CPA, no estudo realizado pelo INEP em 2009 , pode-se observar que $15,1 \%$ das IES não atendem a legislação. Essa diversificação e balanceamento entre os componentes da CPA são fundamentais para o enriquecimento do processo de autoavaliação da instituição, possibilitando uma visão diferenciada por cada agente para uma mesma dimensão analisada.

Em relação ao inciso II, a ampla divulgação de sua composição e de todas as suas atividades, as instituições devem tornar público a composição da CPA para toda a sociedade, realizando uma ação mais intensa com toda a comunidade acadêmica. Um processo de divulgação eficaz é imprescindível para que toda a comunidade possa contribuir com o processo de autoavaliação. A disseminação das atividades realizadas, incluindo o retorno aos agentes participantes da avaliação torna um processo de maior credibilidade.

Segundo Peixoto (2009), questões como a demora em divulgar, mobilizar e tornar públicos os resultados da avaliação, a ausência de mecanismos ágeis para realizar as mudanças identificadas, e a falta de clareza quanto ao papel da avaliação institucional, estão relacionadas ao baixo grau de institucionalização da avaliação nas universidades federais podendo comprometer o êxito do processo.

\section{Caminhos da Pesquisa nas IES em Salvador}

O universo estabelecido para realização da pesquisa constituiu-se das quarenta e quatro faculdades privadas localizadas na cidade de Salvador com status de ativa no site do e-mec (BRASIL, 2011b). Sendo que, dessas quarenta e quatro instituições, oito não foram possíveis de serem analisadas, pois no momento da realização da pesquisa sete não estavam em funcionamento, seja por des- 
credenciamento do MEC ou por descontinuidade das atividades educacionais e uma é a faculdade na qual a pesquisadora atua como coordenadora da CPA, fator que influenciaria diretamente nas respostas apresentadas no questionário.

A pesquisadora contatou, via e-mail ou por telefone, todas as outras trinta e seis instituições de ensino com o propósito de obter a informação de quem é o(a) responsável pela CPA da referida instituição para que posteriormente pudesse falar sobre a problemática da pesquisa.

Dessas trinta e seis faculdades, quinze não responderam ao e-mail enviado ao coordenador da CPA, duas não foi possível estabelecer o contato com o coordenador, pois estavam fora do país em férias ou defesa de doutorado. Tiveram ainda, cinco faculdades que estavam em recesso no período da pesquisa e por isso os números de telefone informados não atendiam. Por fim, a pesquisadora obteve o retorno de quatorze faculdades, o que representa um percentual de aproximadamente 39\% em relação às trinta e seis faculdades em funcionamento.

Os sujeitos da pesquisa são os treze coordenadores das $\mathrm{CPAs}^{3}$ das Faculdades Privadas de Salvador que autorizaram a realização da pesquisa. A opção pela escolha dos coordenadores da CPA não é por ele ser o único envolvido nesse processo, mas sim pelo fato de o mesmo ser um ator de suma relevância dentro desse processo, atuando como mediador das políticas educacionais.

O instrumento de coleta de dados utilizado foi o questionário. Para Martins e Theóphilo (2009, p. 93), o questionário "trata-se de um conjunto ordenado e consistente de perguntas a respeito de variáveis e situações que se deseja medir ou descrever". E para Erthal (2003, p. 49) o questionário é uma "lista de perguntas usada para obter informações sobre opiniões e atitudes dos indivíduos".

O questionário ${ }^{4}$ foi subdividido em quatro seções: Perfil do coordenador da CPA; Composição da CPA; Atuação dos membros da CPA, e o processo de autoavaliação na instituição de ensino.

Em seguida, foi realizada uma comparação dos resultados obtidos a partir da aplicação dos questionários com os requisitos definidos pela CONAES como sendo essenciais para medir o nível de implantação do processo de autoavaliação nas Faculdades Privadas de Salvador, tais como: a existência de uma equipe de coordenação para realizar este trabalho, participação da comunidade acadêmica e da comunidade externa, compromisso explícito dos dirigentes das IES, sistematização de informações válidas e confiáveis, o uso efetivo dos resultados no processo avaliativo e as etapas/atividades inerentes ao processo de autoavaliação.

3 Existem duas Faculdades que são mantidas pela mesma mantenedora, portanto possuem CPA única.

4 Este questionário foi elaborado com a colaboração da pesquisadora Camila de Sousa Pereira Guizzo. 


\section{Análise e Discussão dos Dados}

Para estabelecer o nível de implantação do processo de autoavaliação em cada faculdade pesquisada foram utilizados dez critérios para análise do processo, baseados nas etapas e requisitos inerentes ao processo de autoavaliação, tais como: Existência da CPA para coordenar o processo de autoavaliação; Sensibilização da comunidade acadêmica e externa; Projeto de Avaliação; Participação da comunidade acadêmica; Participação da comunidade externa; Sistematização das informações válidas e confiáveis; Compromisso explícito dos dirigentes das IES, a partir do uso efetivo dos resultados; Relatório do processo de autoavaliação; Divulgação do resultado do processo de autoavaliação, e o Balanço Crítico do processo de autoavaliação.

Para cada critério estabelecido, foram atribuídas notas conforme a escala apresentada no Quadro 1 e calculada uma média aritmética de cada faculdade.

\section{Quadro 1 - Escala das notas utilizadas no diagnóstico do processo de autoavaliação}

\begin{tabular}{|c|l|}
\hline Nota & \multicolumn{1}{|c|}{ Descrição } \\
\hline 1 & Quando o requisito ou etapa do Processo de Autoavaliação for inexistente \\
\hline 2 & $\begin{array}{l}\text { Quando o requisito ou etapa do Processo de Autoavaliação estiver } \\
\text { implementado de forma insuficiente }\end{array}$ \\
\hline 3 & $\begin{array}{l}\text { Quando o requisito ou etapa do Processo de Autoavaliação estiver } \\
\text { implementado de forma suficiente }\end{array}$ \\
\hline 4 & $\begin{array}{l}\text { Quando o requisito ou etapa do Processo de Autoavaliação estiver } \\
\text { implementado de forma muito boa }\end{array}$ \\
\hline 5 & $\begin{array}{l}\text { Quando o requisito ou etapa do Processo de Autoavaliação estiver } \\
\text { implementado de forma muito excelente }\end{array}$ \\
\hline
\end{tabular}

Fonte: Próprio autor

Com relação ao primeiro critério estabelecido, a existência da CPA para coordenar o processo de autoavaliação, das treze CPAs analisadas, aproximadamente $46 \%$ estão com notas 1 ou 2 e $54 \%$ com notas variando entre 3 , 4 e 5 . É importante ressaltar que apenas uma faculdade informou que a CPA estava inativa devido a falta de comprometimento da alta direção.

A Portaria $\mathrm{n}^{\circ} 2.051 / 04 \mathrm{em}$ seu artigo $7^{\circ}, \S 2^{\circ}$ determina que a forma de composição, a duração do mandato dos seus membros, a dinâmica de funcionamento e as atribuições da CPA devem ser registradas em regulamentação própria da IES (BRASIL, 2004d). 
Todos os treze coordenadores da CPA que responderam ao questionário informaram seguir as diretrizes designadas na portaria. Logo, analisando os relatórios de autoavaliação e os sites das faculdades objeto deste estudo ${ }^{5}$, foi possível identificar que uma faculdade não atende ao estabelecido na portaria. Visto que, possui oito representantes do corpo docente na sua comissão de um total de quinze membros. Desrespeitando assim o inciso I do art. 11 da Lei 10.861 onde determina que é vedada a composição que privilegie a maioria absoluta de um dos segmentos.

Quanto aos critérios de sensibilização e divulgação dos resultados do processo, a referida portaria estabelece também que deve haver ampla divulgação da composição da CPA e de todas as suas atividades. Dois pontos principais indicam que a sensibilização / divulgação não ocorre de forma eficiente na maioria das faculdades:

a) apenas $50 \%$ das faculdades analisadas divulgam em seus sites informações sobre a CPA;

b) no momento em que a pesquisadora estabeleceu o primeiro contato com as trinta e seis faculdades privadas de Salvador, aproximadamente 69\% destas não sabiam informar quem era o responsável pela CPA da sua instituição e muitas delas não sabiam nem mesmo o que era CPA.

Esses dados indicam que é necessária uma ampla divulgação das informações referente a CPA para toda a comunidade acadêmica, principalmente o corpo técnico administrativo que na maioria das vezes são os que estabelecem o primeiro contato com a comunidade externa.

Mesmo assim, a faculdades insistem em afirmar que $85 \%$ considera ser um processo contínuo para toda a comunidade acadêmica. Apesar de ser mencionado por algumas instituições que a CPA é pouco conhecida e evidenciado quando analisado os dados acima.

Mesmo sendo identificada como uma das atividades na etapa de preparação do processo de autoavaliação ainda existe Faculdades (15\%) que não possuem um Projeto de Autoavaliação para nortear todo o processo e definir as diretrizes, estratégias e os caminhos a serem percorridos no processo de autoavaliação.

A ausência desse projeto de avaliação pode ser identificada como uma das causas para a falta de conhecimento da CPA por parte da comunidade acadêmica, uma vez que esse deveria ser o instrumento norteador de todo o processo avaliativo.

5 Não foi possível obter a informação da composição da CPA de todas as 14 faculdades pesquisadas, visto que nem todas disponibilizam esta informação nos seus respectivos sites e/ou relatórios de autoavaliação. 
Para os critérios de participação da comunidade acadêmica e externa, apesar do Gráfico 1 demonstrar que a grande maioria dos coordenadores da CPA concorda totalmente ou concorda em parte com a atuação ativa dos segmentos do corpo técnico administrativo, discente e docente das Faculdades no processo de autoavaliação, quando os coordenadores das CPAs foram questionados para sinalizar quais as maiores dificuldades encontradas para desenvolver o processo de autoavaliação a principal resposta foi quanto a participação e conscientização destes agentes no processo de autoavaliação.

\section{Gráfico 1 - Participação ativa dos membros da CPA no processo de autoavaliação}

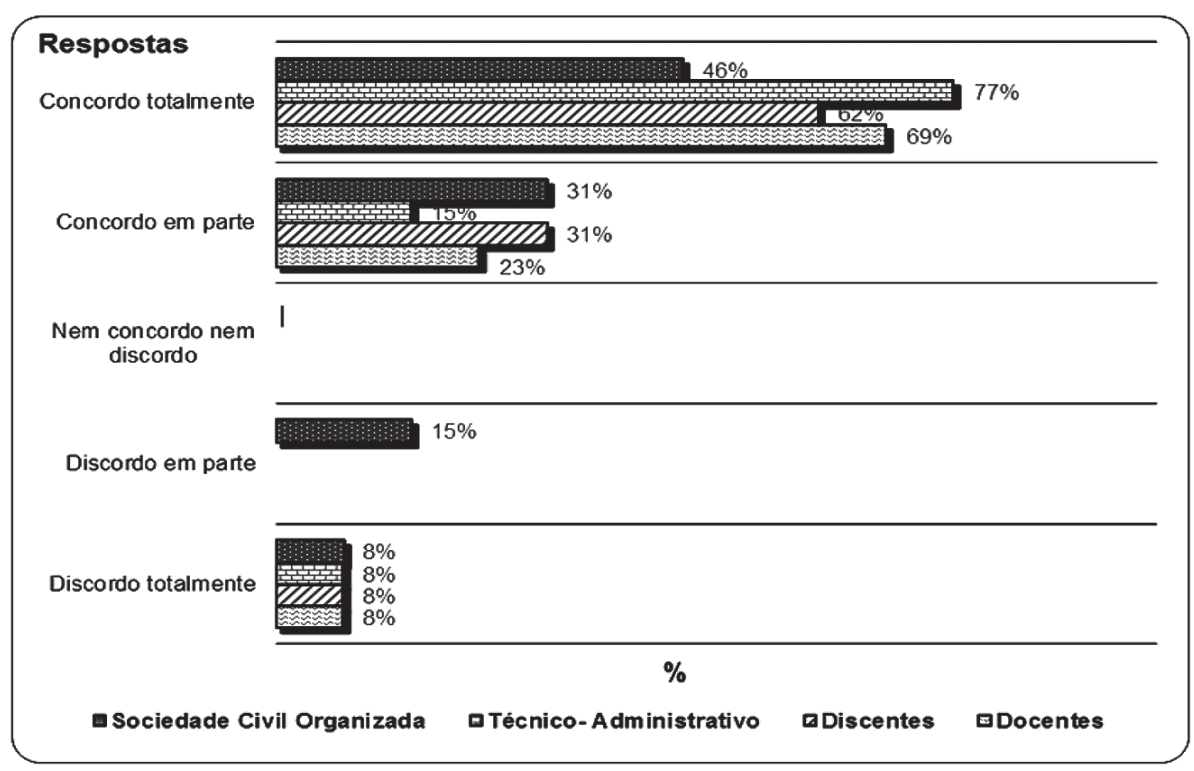

Fonte: Próprio autor

Quanto ao segmento da sociedade civil organizada, este realmente pode ser considerado um ponto de melhoria no processo de autoavaliação. Duas das faculdades analisadas afirmam encontrarem dificuldades em fazer com que esse segmento atue de forma ativa, e possa trazer contribuições para o processo e consequentemente para a melhoria continua do processo educacional.

Andriola citado por Peixoto (2009, p. 22), ao analisar os desafios enfrentados pelas CPAs, destaca a importância da sensibilização da comunidade interna e do incentivo à mobilização dos atores institucionais para participar do processo. 
De certa forma, Andriola recomenda o aumento do grau de informação sobre a sistemática avaliativa e também a necessidade de desmistificar a avaliação como sinônimo de punição e de estabelecimento de "rankings". O autor destaca ainda que quando implementada essas ações, os resultados são positivos com uma elevação da consciência da comunidade interna sobre a importância da avaliação, o estímulo ao seu engajamento nos debates para buscar soluções inovadoras, e a facilitação da formulação e execução do planejamento.

O levantamento de dados e informações deve ser realizado de forma que contemple todas as dimensões do SINAES mencionadas na Lei 10.861 , no seu artigo $3^{\circ}$, para que possibilite uma maior riqueza no momento da análise dos dados.

Os coordenadores da CPA pontuaram as dimensões I, V e X como sendo as de maior dificuldade na obtenção dos dados e consequentemente a sua análise no relatório de autoavaliação. Contudo, é importante mencionar que três Faculdades não marcaram nenhuma opção e informaram não ter dificuldades em nenhuma das dez dimensões. Algumas Faculdades pontuaram que as dimensões $\mathrm{V}$ e X eram consideradas difíceis por conta da natureza dos dados de pessoal e financeiro, respectivamente. Por serem instituições privadas, existe o receio em divulgar dados dessa natureza para toda a comunidade acadêmica.

Para analisar a terceira atividade da etapa de desenvolvimento do processo de autoavaliação, foi solicitado que os coordenadores da CPA avaliassem a utilização dos dados oriundos da autoavaliação no processo de tomada de decisões por parte dos dirigentes. Somente uma faculdade informou não utilizar os dados oriundos do processo de autoavaliação por conta da CPA estar inativa. Todas as outras faculdades afirmaram existir uma utilização efetiva dos dados do processo de autoavaliação e reforçam a importância que é dada aos pontos fracos/fragilidades identificadas neste processo. Por isso, é importante ressaltar que as faculdades sinalizaram que por serem faculdades privadas, existe uma limitação orçamentária que as obriga a trabalhar com prioridades nas fragilidades detectadas. Por conta disso, na maioria das vezes essas fragilidades estão associadas a questões de infraestrutura da instituição.

A etapa de consolidação inicia-se com a construção do relatório. Apesar do estudo realizado pelo INEP em 2009, evidenciar que apenas 12,2\% dos relatórios de autoavaliação analisados podem ser considerados completos, ou seja, aquele que em sua maior parte ou na totalidade das dimensões as potencialidades, fragilidades, sugestões de encaminhamentos, compara com a avaliação anterior e demonstra avanços, 92\% dos coordenadores da CPA, concordam com a participação ativa de todos os membros na construção do relatório de autoavaliação. 
Iniciando a análise do processo de divulgação quando questionado se todos os segmentos da CPA prestam informações de forma permanente ao segmento que representam $76 \%$ dos coordenadores da CPA, entendem que sim. Todavia, também é fácil observar que algumas instituições externam ter dificuldades no processo de divulgação das ações executadas pela Comissão Própria de Avaliação.

Apenas uma faculdade relatou que a CPA está inativa na instituição, principalmente pela falta de envolvimento efetivo dos dirigentes da mesma. Informando ainda que será realizada uma reestruturação do PDI da instituição com o objetivo de iniciar um novo ciclo de avaliação.

Segundo Peixoto (2009), questões como a demora em divulgar, mobilizar e tornar públicos os resultados da avaliação, a ausência de mecanismos ágeis para realizar as mudanças identificadas, e a falta de clareza quanto ao papel da avaliação institucional, estão relacionadas ao baixo grau de institucionalização da avaliação nas universidades federais podendo comprometer o êxito do processo. De acordo com os relatos das faculdades aqui pesquisadas, essas questões também podem influenciar negativamente na participação da comunidade acadêmica no processo de avaliação institucional.

Ao final do processo de autoavaliação deve ser feita uma análise detalhada de todo o processo destacando, os pontos fortes e analisando os pontos fracos, de modo que permita uma melhoria contínua neste processo. Isso é o que o INEP, chama de Balanço Crítico. Conforme os coordenadores das CPAs pesquisadas, 92\% realizam este balanço crítico.

Essa dificuldade em conseguir a participação da comunidade acadêmica no processo de autoavaliação perpassa por algumas questões como: a ausência da cultura de avaliação na instituição, fazendo com que a comunidade acadêmica não enxergue o processo como sendo punitivo ou de premiação. Mas, sim como um processo que objetiva a melhoria do processo educacional. Também, pode-se relacionar com a falta de crença nas consequências do processo. Muitas vezes a comunidade acadêmica, não consegue relacionar as ações de melhoria executadas a partir das fragilidades identificadas no processo de autoavaliação.

Após a análise de cada critério e o estabelecimento de uma média para todas as treze CPAs analisadas, foi atribuído um conceito ao processo de autoavaliação que pode variar desde a não implantação do processo até a sua implantação de forma excelente (Quadro 2). 


\section{Quadro 2 - Faixas referente ao nível de implementação processo de autoavaliação}

\begin{tabular}{|c|c|}
\hline Média & Conceito \\
\hline 1 a 1,99 & Processo de Autoavaliação não implantado \\
\hline 2 a 2,99 & Processo de Autoavaliação implantado de forma insuficiente \\
\hline 3 a 3,99 & Processo de Autoavaliação implantado de forma suficiente \\
\hline 4 a 5 & Processo de Autoavaliação implantado de forma excelente \\
\hline
\end{tabular}

Fonte: Próprio autor

O resultado evidenciou a necessidade de uma melhoria nesse processo de autoavaliação, visto que aproximadamente $50 \%$ das faculdades pesquisadas encontram-se com um nível de implantação insuficiente, o que significa que não atende aos requisitos mínimos estabelecidos pela CONAES e uma faculdade está com a CPA inativa.

É importante que as instituições de ensino de uma forma geral tenham consciência da importância do processo de autoavaliação, para a melhoria nos processos internos das IES, e principalmente na busca da melhoria da qualidade do ensino superior no Brasil.

\section{Conclusões}

Esse artigo procurou identificar o nível de implantação do processo de autoavaliação nas faculdades privadas de Salvador, na visão dos coordenadores da CPA, e para tal aplicou um questionário com treze coordenadores de CPA.

Em relação aos critérios estabelecidos para essa análise o considerado mais crítico e com uma abrangência maior em todas as faculdades pesquisadas é a participação da comunidade acadêmica no processo de autoavaliação. As instituições de uma forma geral precisam identificar formas de conseguir uma participação mais efetiva da comunidade acadêmica. Logo em seguida vem a participação da comunidade externa.

Critérios como a existência da CPA para coordenar o processo e a sensibilização para a comunidade (interna e externa) vêm logo em seguida para concluir itens da primeira etapa do processo de autoavaliação, onde podem ser identificadas algumas oportunidades de melhoria:

a) maior divulgação da existência e atribuições da CPA para a comunidade acadêmica; 
b) executar as ações oriundas do processo de autoavaliação e dar ciência a comunidade acadêmica;

c) participação mais ativa do representante da sociedade civil;

d) oportunizar mais encontros/seminários dos coordenadores da CPA das diversas instituições de ensino;

e) identificar formas de envolver a comunidade acadêmica no processo de autoavaliação, como por exemplo, transformando em horas de atividades complementares para os alunos e horas de atividades extra classe para os docentes.

Quanto a segunda etapa, onde engloba critérios como a sistematização da informações válidas e confiáveis e o compromisso explícito dos dirigentes da IES, pode-se identificar algumas oportunidades de melhoria:
a) maior divulgação do Plano de Desenvolvimento Institucional (PDI) para a comunidade acadêmica;
b) Existência de um sistema informatizado para coleta dos dados;
c) Utilizar o resultado da autoavaliação como dado de entrada para a elaboração do orçamento da Faculdade.

$\mathrm{Na}$ última etapa, as fragilidades detectadas foram relatórios incompletos, divulgação ineficaz do resultado do processo de autoavaliação e a ausência da retroalimentação do processo. Sendo possível estabelecer as seguintes oportunidades de melhoria:

a) Identificar formas mais eficazes de divulgação do resultado mais eficazes do que murais e sites, a exemplo de, jornais da Faculdade e grupos focais;

b) evidenciar no relatório de autoavaliação o balanço crítico realizado do processo de autoavaliação do ano anterior;

c) divulgar para toda a comunidade acadêmica a execução de ações identificadas pelo processo de autoavaliação, não deixando somente para o próximo ano. 


\section{Referências}

AUGUSTO, Rosana; BALZAN, Newton Cesar. A vez e a voz dos Coordenadores das CPAs de Campinas que integram o SINAES. Avaliação, Campinas, Sorocaba, v. 12, n. 4, p. 597-624, dez. 2007.

BRASIL. Ministério da Educação. Análise dos relatórios de autoavaliação das instituições de educação superior. Brasília: MEC, 2011. v.1; v.3.

. Ministério da Educação. Sistema e-MEC. Brasília, 2011b. Disponível em: <http://emec.mec.gov.br/>. Acesso em: 5 maio 2011. . Ministério da Educação. Avaliação externa das instituições de educação superior: diretrizes e instrumentos. Brasília: MEC, 2006. . Ministério da Educação. Diretrizes para a Avaliação das Instituições de Educação Superior. Brasília: MEC, 2004a. . Ministério da Educação. Lei no 10.861, de 14.04.2004. Institui o Sistema de Avaliação da Educação Superior - SINAES e dá outras providências. Brasília: MEC, 2004b.

. Ministério da Educação. Portaria no 2.051, de 09/07/2004. Regulamenta os procedimentos de avaliação do Sistema Nacional de Avaliação da Educação Superior (SINAES), instituído na Lei no 10.861 , de 14 de abril de 2004. Diário Oficial da União, Brasília, n. 32, seção 1, p. 12, 12 jul. 2004d.

CARNEIRO, Breno Pádua Brandão. As comissões próprias de avaliação frente ao processo de regulação do ensino superior privado, 2007. 73 f. Dissertação (Mestrado em Educação).- Faculdade de Educação, Universidade do Estado da Bahia, Salvador, 2007.

ERTHAL, Tereza Cristina. Manual de psicometria. 7. ed. Rio de Janeiro: Jorge Zahar, 2003.

MARTINS, Gilberto de Andrade; THEÓPHILO, Carlos Renato. Metodologia da investigação científica para ciências sociais aplicada. 2. ed. São Paulo: Atlas, 2009. 
PEIXOTO, Maria do Carmo de Lacerda. A avaliação institucional nas universidades federais e as comissões próprias de avaliação. Avaliação, Campinas, Sorocaba, v. 14, n. 1, p. 9-28, mar. 2009.

SINAES -Sistema Nacional de Avaliação da Educação Superior: da concepção à regulamentação. 5. ed. revisada e ampliada. Brasília: Instituto Nacional de Estudos e Pesquisas Educacionais Anísio Teixeira, 2009.

SOUSA, Clarilza Prado de. Avaliação de instituições de ensino superior:discutindo a necessidade de diretrizes metodológicase estratégias de implantação. Estudos em Avaliação Educacional, São Paulo, v. 17, n. 35, set./dez. 2006.

TRIGUEIRO, Michelangelo G. S. A avaliação institucional e a redefinição das estruturas e modelos de gestão das instituições de ensino superior do país. Avaliação, Campinas, v. 9, n. 3, p 11-30, set. 2004.

Eniel do Espírito Santo - Universidade Federal do Recôncavo da Bahia Cruz das Almas | BA | Brasil. Contato: enielsanto@gmail.com Xisto Lucas Travassos - Centro Integrado de Manufatura e Tecnologia do Sistema FIEB Salvador | BA | Brasil. Contato: lucas.travassos@fieb.org.br Sabrina Oliveira Caribé - Faculdade de Tecnologia SENAI CIMATEC Salvador | BA | Brasil. Contato: sabrina.caribe@gmail.com

Artigo recebido em 21 de janeiro de 2013 e aprovado em 6 de junho de 2013. 